\title{
An association between Helicobacter pylori infection and cognitive function in children at early school age: a community-based study
}

\author{
Khitam Muhsen ${ }^{1}$, Asher Ornoy ${ }^{2}$, Ashraf Akawi ${ }^{1}$, Gershon Alpert ${ }^{3}$ and Dani Cohen ${ }^{1 *}$
}

\begin{abstract}
Background: H. pylori infection has been linked to iron deficiency anemia, a risk factor of diminished cognitive development. The hypothesis on an association between $\mathrm{H}$. pylori infection and cognitive function was examined in healthy children, independently of socioeconomic and nutritional factors.

Methods: A community-based study was conducted among 200 children aged 6-9 years, from different socioeconomic background. H. pylori infection was examined by an ELISA kit for detection of H. pylori antigen in stool samples. Cognitive function of the children was blindly assessed using Stanford-Benit test $5^{\text {th }}$ edition, yielding IQ scores. Data on socioeconomic factors and nutritional covariates were collected through maternal interviews and from medical records. Multivariate linear regression analysis was performed to obtain adjusted beta coefficients.
\end{abstract}

Results: H. pylori infection was associated with lower IQ scores only in children from a relatively higher socioeconomic community; adjusted beta coefficient -6.1 (95\% Cl -11.4, -0.8) ( $P=0.02)$ for full-scale IQ score, -6.0 $(95 \% \mathrm{Cl}-11.1,-0.2)(P=0.04)$ for non-verbal IQ score and $-5.7(95 \% \mathrm{Cl}-10.8,-0.6)(P=0.02)$ for verbal IQ score, after controlling for potential confounders.

Conclusions: H. pylori infection might be negatively involved in cognitive development at early school age. Further studies in other populations with larger samples are needed to confirm this novel finding.

\section{Background}

In the past few years there have been several studies, mainly from developing countries, suggesting negative influence of gastrointestinal infections in childhood on cognitive function [1,2], psychomotor development [3], and school readiness and performance [4], even when socioeconomic variables and nutritional status were controlled $[1,2,4]$. Helicobacter pylori is another microorganism acquired in early childhood that colonizes the stomach [5-8]. The prevalence of $H$. pylori infection reaches $50 \%$ by the age of five years in developing countries compared with $10 \%-20 \%$ in developed countries [6-8]. H. pylori infection is mostly asymptomatic and about $20 \%$ of infected people develop a clinical disease, usually in adulthood. H. pylori causes chronic gastritis,

\footnotetext{
* Correspondence: dancohen@post.tau.ac.il

'Department of Epidemiology and Preventive Medicine, School of Public Health, Sackler Faculty of Medicine, Tel-Aviv University, Ramat Aviv, Tel Aviv, 69978, Israel

Full list of author information is available at the end of the article
}

peptic ulcers and increases the risk gastric carcinoma $[6,8,9]$. H. pylori infection was also linked to depletion in iron stores in both adults and children [10-15]. It was shown that $H$. pylori infection was significantly associated with a 2.8 fold higher prevalence of iron deficiency anemia and a 1.38 fold higher prevalence of iron deficiency [13]. In a sero-epidemiologic study, H. pylori sero-positivity was linked to lower ferritin levels in Israeli Arab children [12]. Anemia and iron deficiency anemia were negatively correlated with cognitive development and school performance [16-19]. We therefore hypothesized that $H$. pylori infection might negatively affect cognitive development. Hypotheses on potential negative effects of $H$. pylori infection on developmental outcomes in children were raised before [20,21], however, to the best of our knowledge the association between $H$. pylori infection and cognitive development was not assessed before.

The aim of the study was to examine the association between $H$. pylori infection and cognitive development 
at early school age, independently of socioeconomic and nutritional factors. If this association is confirmed it would be of both clinical and public health importance.

\section{Methods}

\section{Study population, setting and design}

The current study focuses on a population under transition; the Israeli Arab population. This population has unique characteristics, in terms of infrastructure, health care and education systems which are similar to those existing in developed countries, while the rates of $H$. pylori infections and anemia are comparable to those reported from developing countries. The Israeli Arab population comprises $20 \%$ of the Israeli population [22]. The Israeli Arabs reside mostly in separate locations than the Jewish population, and usually in rural areas. The Israeli Arab population has lower educational levels and socioeconomic status as compared with the Jewish population [22], nevertheless this population is in positive transition, with ongoing improvement of the educational level and medical system. Israeli Arabs have mandatory health insurance according to the national health insurance law. The vaccination coverage in this population is over $95 \%$.

This retrospective cohort study was conducted in 2007 2009, among children who participated in a previous project on $H$. pylori infection in 2004, when they were 3-5 years of age. Fifty percent of the children were $H$. pylori positive at this age [23]. Families of these children live in three villages in northern Israel. There are about 150,000 Muslim Arab inhabitants living in this region, with 3914 live births in 2007 [24]. Two of the villages have approximately 10,000 residents, and the third one is inhabited by about 14,000 residents. According to the Central Bureau of Statistics, one village belongs to cluster 2-socioeconomic status (SES), one belongs to cluster 3-SES, and the third village belongs to cluster 4-SES (for more details on the study villages see additional file 1 ). The clusters are on a scale of 1-10, the lower the index, the lower the SES [25]. At the national level, these villages are of low and intermediate SES levels [25], but given the variation among them, they were labeled in the present study as low, intermediate and high SES village. Drinking water supply in these villages is piped, and all households are connected to the national electricity company similarly to the rest of the country. Connection to the cable television and internet networks is also available. The educational system in these villages includes kindergartens, primary and high schools. The three villages were selected to represent different socioeconomic background within the Arab population. The characteristics of the selected villages are similar to the Israeli Arab population. For example the median age in the Israeli Arab population is 20 years [22], as compared with 18-21 years in the three villages [25]. 34\% of the families in the Israeli Arab population have $\geq 6$ persons, and $21 \%$ of the women hold a job [22], as compared with $33 \%$ and $24 \%$, respectively in the study sample. The mean number of rooms per a household is 3.7, and the median year of schooling is 11.312.0 in the Israeli Arab population [22,26], as compared with 3.8 and 10 years, respectively in the study sample.

In the original study, we used cluster sampling procedure, in which 9 kindergartens (3 per village) were sampled from the kindergartens in each village. Parents of all children from each selected kindergarten were offered to participate in the study, through personal meetings at the candidates' homes.

In the current study, children born at a gestational age of 34 week or more and a birth weight of $2 \mathrm{~kg}$ or more were eligible to participate in the study. Among 289 participants of the 2004 study, 3 relocated their residence place, 5 could not be located, 1 child deceased due to cancer, 2 could not participate since their mothers deceased during the study period, 7 children were excluded due to birth weight of less than $2 \mathrm{~kg}$ or birth week less than 34 . Nine additional children were excluded due to thalassemia minor ( 3 children), type- 1 diabetes ( 1 child), Glucose-6-phosphate dehydrogenase deficiency with anemia ( 1 child), major heart defect (1 child), panhypopituitarism (1 child), hemophilia (1 child), and significant developmental delay requiring therapy (1 child). These conditions might affect cognitive function directly or might be associated with other conditions related with cognitive function e.g. hemoglobin levels. Among parents of 263 eligible children who were contacted through home visits, 41 refused to participate in the study and 222 consented, of these, 200 complied with the study procedures (i.e. compliance rate of $76 \%$ ).

The Institution Review Boards of Tel Aviv University and of Hillel Yaffe Medical Center approved the study. Written informed consent was obtained from the parents' participants.

\section{Data collection}

Information on household and socioeconomic characteristics was obtained through personal interviews held with the mothers, by trained Arabic-speakers interviewers. The questionnaire included information on age, sex, village of residence, maternal education, maternal age, paternal education, monthly family income, number of persons living in the household, and number of rooms in the household. Crowding index was calculated by dividing the number people living in a household by the number of rooms in a household.

\section{The outcome variable-Cognitive function}

Cognitive function was measured by Intelligence Quotient (IQ) score using Stanford-Binet- $5^{\text {th }}$ edition (SB5) test, performed by a trained Arabic speaking psychologist. 
The following parameters were assessed and reported here: full-scale IQ, non-verbal and verbal IQ. The test was performed at standard conditions, lasting on average 45 minutes. The psychologist was blinded to $H$. pylori infection status and other independent variables. The SB5 was scored with the SB5 Scoring Pro, a Windows ${ }^{\circledR}$ based software program.

\section{Collection of stool specimens}

Fresh stool specimens were obtained from children by collection cups, using the same protocol and means. After being kept and transported in cool conditions, specimens were aliquoted and frozen at the research laboratory at $-70^{\circ} \mathrm{C}$ until tested.

\section{Detection of $H$. pylori infection - The independent variable}

A commercial enzyme linked immunoassay kit (Premier Platinum HpSA PLUS, Meridian Bioscience, Inc., Cincinnati, Ohio) employing monoclonal anti- $H$. pylori antibody adsorbed to 96-well microtiter plates was used to detect $H$. pylori antigen in stools according to the manufacturer's instructions. Optical density values of $\geq 0.140$ were considered positive and $<0.140$ were considered negative.

\section{Additional independent variables Current hemoglobin levels}

Blood collected by finger lancing was used for hemoglobin measurement employing a portable hemoglobinometer (Hemocue Hb 201+, Sweden).

\section{Hemoglobin levels in early childhood}

Infants in Israel are screened for iron deficiency anemia at the age 9-18 months, and the results of the participants' tests were collected from medical records.

\section{Anthropometric measurements}

Anthropometric measurements were performed by specially trained registered nurses. Body weight was measured to the nearest 0.1 kilogram using an analog scale (calibrated before use), and height (to the nearest 0.1 centimeter) with a stadiometer. Information on anthropometric measurements in early childhood (ages 18-30 months) was obtained from medical records. $\mathrm{Z}$ scores of height for age (HAZ), weight for height (WHZ), and Body Mass Index for age (BMIZ) were calculated using Epi/Info software (Center for Disease Control and Prevention, Atlanta, Georgia (CDC)). The calculations were based on the 2000 CDC growth reference curves, which were primarily based on the US National Health Examination (NHES) and the National Health and Nutrition Examination Surveys (NHANES). BMI was calculated as: weight $(\mathrm{kg}) /$ height $(\mathrm{m})^{2}$.

\section{Socioeconomic status (SES)}

SES was assessed by several parameters: (1) community SES rank as classified by the Israel Central Bureau of
Statistics, (2) household socioeconomic characteristics: (a) maternal education, (b) paternal education, (c) crowding index, and (d) reported family income.

In addition, a composite variable of individual level SES was created using the parameters: maternal education, paternal education, monthly family income, and crowding index. The summative scoring of this composite index was as following: each child was accredited one point if maternal education level was $\geq 10$ years and 0 points if maternal education level was $<10$ years, one point if paternal education level was $\geq 10$ years and 0 points if paternal education level was $<10$ years, one point if the monthly family income was $>4000 \mathrm{New}$ Israeli Shekels (NIS) and 0 points if the monthly family income was $\leq 4000$ NIS, one point if the crowding index was below the median level (1.61 persons/room) and 0 if the crowding index was $\geq 1.61$. The higher the summative score, the better the socioeconomic status. Scoring below the median level was defined as low socioeconomic status, while scoring the median level or higher was classified as high socioeconomic status.

\section{Statistical analysis}

Differences between the villages in the independent and the outcome variables were examined using Chi square test and one way analysis of variance (ANOVA). The difference in the mean IQ levels between $H$. pylori infected children and uninfected ones was examined using Student $t$ test. Student $t$ test was also used to examine the difference in IQ scores in relation to sex and categorical socioeconomic characteristics. Pearson coefficients were calculated to examine the correlations between IQ levels and independent continuous variables (current hemoglobin levels, hemoglobin levels in early childhood, HAZ and WHZ scores in early childhood, and current BMIZ scores). Multiple linear regression models were used to obtain adjusted $\beta$ coefficients of effect estimates, while controlling for other covariates in the models. Variables that were associated with IQ scores in the univariate analysis $(P<0.1)$ were included in the multivariate analysis. Additional multivariate analyses were performed, while including in the model $H$. pylori infection, the composite SES index, hemoglobin levels and current BMIZ score as a measure of nutritional status. Since socioeconomic features might affect cognitive function and given the differences in socioeconomic status among the three villages, we hypothesized that IQ scores might also differ among the villages. In addition, the three villages differed significantly in the prevalence of $H$. pylori infection, being highest in the low SES village [16]. Thus the statistical analyses were stratified by village of residence. In all analyses two tailed $\mathrm{P}<0.05$ was considered statistically significant. Data were analyzed using SPSS software (SPSS Inc, Chicago, IL) version 17. 


\section{Results}

Two hundred children (56.5\% males) with a mean age of 7.8 (SD 0.84) years were included in the study. Maternal and paternal education levels were lowest in the low SES village, and more crowded households were in this village (Table 1 ). The prevalence of $H$. pylori infection was significantly higher among children from the low SES village than other children. The mean full-scale IQ, non-verbal IQ and verbal IQ levels of children from the low SES village were significantly lower than those of children from the intermediate and high SES villages (Table 1). These findings support our a-priori hypothesis regarding the differences between the villages in the exposure and outcome variables.

\section{Univariate analysis}

In the high SES village, the mean full-scale IQ and nonverbal IQ levels were significantly lower among children with low maternal education. $H$. pylori infected children had significantly lower full-scale IQ, non-verbal and verbal IQ scores, as compared with uninfected ones. Current hemoglobin level was significantly correlated with IQ scores (Table 2). There was no significant association between sex, paternal education, living in crowded households, hemoglobin level, HAZ and WHZ scores in early childhood, and current BMIZ score and IQ scores, neither was the composite SES index associated with IQ scores (Table 2).

In the intermediate SES village, the mean level of fullscale IQ, non-verbal IQ and verbal IQ was significantly lower in boys than girls, and in children with low maternal and paternal education and from a lower SES (Table 3). No significant association was found between $H$. pylori infection, living in crowded households, hemoglobin levels, HAZ score in early childhood, and IQ scores. Borderline statistically significant correlations were found between current hemoglobin levels, current BMIZ score, WHZ score in early childhood and IQ parameters (Table 3).
In the low SES village, significantly lower mean levels of full-scale IQ and verbal IQ were found among children with low maternal education and those who lived in crowded households (Table 4). Neither $H$. pylori infection nor SES composite index were associated with IQ parameters. HAZ score in early childhood was significantly correlated with IQ levels. A trend of a correlation was observed between hemoglobin levels in early childhood and full-scale IQ and non-verbal IQ scores. No significant association was found between sex, paternal education, current hemoglobin levels, current BMIZ score, WHZ score in early childhood, and IQ parameters (Table 4).

\section{Multivariate analysis}

In the high SES village, the association between $H$. pylori infection and cognitive function remained statistically significant, and the overall reduction was 6.1 points in the full-scale IQ score, 6.0 points in the non-verbal IQ score and 5.7 points in the verbal IQ score (Table 5), after controlling for maternal education, maternal age and current hemoglobin levels. In a second multivariate analysis that included $H$. pylori infection, and controlled for the composite SES index, maternal age, current hemoglobin level and current BMIZ score, $H$. pylori infection was significantly associated with 4 point lower IQ scores: adjusted $\beta$ coefficient -4.1 (95\% CI -6.2, -2.0) $(\mathrm{P}<0.001)$ for full-scale IQ score, -4.2 (95\% CI -6.5, -1.8) $(\mathrm{P}=0.001)$ for non-verbal IQ score and -3.7 $(95 \%$ CI -5.7, -1.7) $(\mathrm{P}<0.001)$ for verbal IQ score.

In the intermediate SES village sex, maternal education and current hemoglobin levels were the main correlates of IQ scores, while in the low SES village, living in crowded households, HAZ score and hemoglobin levels in early childhood were the main correlates (Table 5).

\section{Discussion}

We examined the association between $H$. pylori infection and cognitive development among school age children

Table 1 Characteristics of the participants, 2007-2009

\begin{tabular}{lcccccc}
\hline & All villages & Missing & & \multicolumn{2}{c}{ Village SES } & P value \\
& $\mathbf{N}=\mathbf{2 0 0}$ & $\mathbf{N}(\%)$ & Low $\mathbf{N}=\mathbf{8 3}$ & Intermediate $\mathbf{N}=\mathbf{6 2}$ & High $\mathbf{N}=\mathbf{5 5}$ \\
\hline Maternal education $\geq 10$ years, N (\%) & $100(50.0)$ & - & $15(18.1)$ & $41(66.1)$ & $44(80.0)$ & $<0.001$ \\
\hline Paternal education $\geq 10$ years, N (\%) & $98(52.7)$ & $14(7.0)$ & $22(30.6)$ & $38(61.3)$ & $38(73.1)$ & $<0.001$ \\
\hline Crowding index $>2, N(\%)$ & $58(29.0)$ & - & $47(56.6)$ & $9(14.5)$ & $2(3.6)$ & $<0.001$ \\
\hline Monthly family income $\geq 4000$ NIS, N (\%)* & $74(37.9)$ & $5(2.5)$ & $15(18.3)$ & $31(50.0)$ & $28(54.9)$ & $<0.001$ \\
\hline H. pylori infection, N (\%) & $107(59.1)$ & $19(9.5)$ & $63(87.5)$ & $22(38.6)$ & $22(42.3)$ & $<0.001$ \\
\hline Mean Full-Scale IQ (SD) & $98.9(12.6)$ & - & $90.1(12.0)$ & $106.2(8.5)$ & $104.0(8.9)$ & $<0.001$ \\
\hline Mean Non-Verbal IQ (SD) & $96.6(12.4)$ & - & $88.4(10.9)$ & $103.7(9.8)$ & $100.9(9.8)$ & $<0.001$ \\
\hline Mean Verbal IQ (SD) & $101.6(13.1)$ & - & $92.9(13.8)$ & $108.4(8.0)$ & $107.0(8.4)$ & $<0.001$ \\
\hline
\end{tabular}

* NIS: New Israeli Shekel (1 NIS 3.6 US\$) 
Table 2 Univariate analysis of IQ scores correlates -high SES village ${ }^{a}$

\begin{tabular}{|c|c|c|c|c|}
\hline & & Full-Scale IQ & Non-verbal IQ & Verbal IQ \\
\hline & $\mathbf{N}$ & Mean (SD) & Mean (SD) & Mean (SD) \\
\hline \multicolumn{5}{|l|}{ Sex } \\
\hline Males & 33 & $103.4(9.9)$ & $99.9(10.7)$ & $106.9(9.1)$ \\
\hline Females & 22 & $105.0(7.4)$ & $102.4(8.4)$ & $107.2(7.5)$ \\
\hline \multicolumn{5}{|l|}{$\begin{array}{l}\text { Maternal } \\
\text { education }\end{array}$} \\
\hline$<10$ years & 11 & $99.5(7.0)$ & $94.7(7.5)$ & $104.4(6.7)$ \\
\hline$\geq 10$ years & 44 & $105.2(9.0)^{*}$ & $102.4(9.8)^{* *}$ & $107.7(8.8)$ \\
\hline \multicolumn{5}{|l|}{$\begin{array}{l}\text { Paternal } \\
\text { education }\end{array}$} \\
\hline$<10$ years & 14 & $103.7(8.9)$ & $99.9(9.9)$ & $107.5(8.1)$ \\
\hline$\geq 10$ years & 38 & $104.5(9.2)$ & $101.6(10.1)$ & $107.2(8.8)$ \\
\hline \multicolumn{5}{|l|}{ Crowding index } \\
\hline$<$ median & 22 & $105.9(8.2)$ & $102.6(8.9)$ & $108.8(8.0)$ \\
\hline$\geq$ median & 33 & $102.8(9.3)$ & $99.8(10.4)$ & $105.8(8.6)$ \\
\hline \multicolumn{5}{|l|}{$\begin{array}{l}\text { Composite SES } \\
\text { index }\end{array}$} \\
\hline LOW SES & 20 & $102.6(8.3)$ & $99.0(9.3)$ & $106.2(7.5)$ \\
\hline High SES & 35 & $104.8(9.3)$ & $102.0(10.1)$ & $107.5(9.0)$ \\
\hline \multicolumn{5}{|l|}{ H. pylori infection } \\
\hline Negative & 30 & $106.3(6.0)$ & $103.4(7.1)$ & $108.9(6.4)$ \\
\hline Positive & 22 & $100.5(11.5)^{* *}$ & $97.2(12.5)^{* *}$ & $103.8(10.2)^{* *}$ \\
\hline $\begin{array}{l}\mathrm{Hb} \text { at early } \\
\text { childhood }^{\mathrm{b}}\end{array}$ & 51 & 0.14 & 0.21 & 0.04 \\
\hline Current Hb level $^{\mathrm{b}}$ & 53 & $0.28^{* *}$ & $0.26^{*}$ & 0.28 \\
\hline $\begin{array}{l}\text { HAZ at early } \\
\text { childhood }^{\text {b }}\end{array}$ & 54 & 0.02 & 0.05 & -0.02 \\
\hline $\begin{array}{l}\text { WHZ at early } \\
\text { childhood }^{\text {b }}\end{array}$ & 54 & -0.04 & -0.02 & -0.08 \\
\hline Current BMIZ & 53 & -0.05 & -0.08 & -0.01 \\
\hline
\end{tabular}

${ }^{\text {a }} \mathrm{P}$ value were obtained by the Student $\mathrm{t}$ test unless otherwise is specified.

${ }^{\mathrm{b}}$ Pearson correlation.

${ }^{*} \mathrm{P}<0.1$, **P $<0.05$.

$\mathrm{Hb}$ : hemoglobin, HAZ: Height for Age Z score, WHZ: Weight for Height Z score, BMIZ: Body Mass Index Z score.

from different socioeconomic background. H. pylori infection was independently associated with a 4 to 6 point lower full-scale IQ score, as well as reduced nonverbal IQ and verbal IQ scores, in children who lived in a relatively higher SES village. To the best of our knowledge there are no published studies on the relationship of $H$. pylori infection with cognitive development.

Previous studies have shown an association between $H$. pylori infection and iron deficiency anemia [13]. In the same cohort of children, we found a 2.8 higher risk for anemia and lower mean ferritin levels at age 6-9 years in $H$. pylori infected children compared with uninfected ones, after controlling for socioeconomic confounders [27]. In a different study, H. pylori seropositivity was associated with increased frequency of low ferritin levels in Arab children in Israel [12]. Iron
Table 3 Univariate analysis of IQ scores correlates -intermediate SES village ${ }^{a}$

\begin{tabular}{lcccc}
\hline & & Full-Scale IQ & Non-Verbal IQ & Verbal IQ \\
\hline & N & Mean (SD) & Mean (SD) & Mean (SD) \\
\hline Sex & & & & \\
Males & 38 & $103.6(7.2)$ & $100.3(7.9)$ & $106.8(7.1)$ \\
Females & 24 & $110.3(9.0)^{* *}$ & $109.2(10.3)^{* * *}$ & $111.0(8.8)^{* *}$ \\
\hline
\end{tabular}

Maternal

education

$\begin{array}{llccc}<10 \text { years } & 21 & 101.1(7.6) & 99.6(9.5) & 103.4(6.6)\end{array}$

\begin{tabular}{llll}
$\geq 10$ years & $41 \quad 108.7(8.0)^{* *} \quad 105.9(9.4)^{* *} \quad 110.0(7.4)^{* * *}$ \\
\hline
\end{tabular}

Paternal

education

$\begin{array}{lllll}<10 \text { years } & 24 & 102.8(8.0) & 100.5(8.8) & 105.1(7.5)\end{array}$

$\begin{array}{lllll}\geq 10 \text { years } & 38 & 108.4(8.3)^{* *} & 105.8(10.0)^{* *} & 110.5(7.5)^{* *}\end{array}$

\begin{tabular}{lllcl}
\hline Crowding index & & & & \\
$<$ median & 31 & $106.5(9.8)$ & $104.2(11.2)$ & $108.5(8.8)$ \\
$\geq$ median & 31 & $106.0(7.2)$ & $103.3(8.4)$ & $108.4(7.3)$
\end{tabular}

Composite SES

index

\begin{tabular}{|c|c|c|c|c|}
\hline Low SES & 29 & $103.4(8.4)$ & $101.5(10.0)$ & $105.2(7.6)$ \\
\hline High SES & 33 & $108.7(7.9)^{* *}$ & $105.7(9.4)^{*}$ & $111.2(7.3)^{* * *}$ \\
\hline \multicolumn{5}{|l|}{ H. pylori infection } \\
\hline Negative & 35 & $106.1(9.8)$ & $104.1(11.0)$ & $107.9(9.2)$ \\
\hline Positive & 22 & 106.5(6.9) & $102.8(8.2)$ & $109.8(6.3)$ \\
\hline $\begin{array}{l}\mathrm{Hb} \text { at early } \\
\text { childhood }\end{array}$ & 43 & -0.15 & -0.08 & -0.22 \\
\hline Current $\mathrm{Hb}$ level ${ }^{\mathrm{b}}$ & 58 & $0.22^{*}$ & $0.22^{*}$ & 0.17 \\
\hline $\begin{array}{l}\text { HAZ at early } \\
\text { childhood }{ }^{b}\end{array}$ & 62 & 0.07 & 0.15 & -0.01 \\
\hline $\begin{array}{l}\text { WHZ at early } \\
\text { childhood }{ }^{b}\end{array}$ & 62 & 0.22 & 0.22 & 0.17 \\
\hline Current BMIZ ${ }^{\mathrm{b}}$ & 58 & $0.25^{*}$ & 0.21 & $0.24^{*}$ \\
\hline
\end{tabular}

${ }^{\mathrm{a}} \mathrm{P}$ value were obtained by the Student $\mathrm{t}$ test unless otherwise is specified.

${ }^{b}$ Pearson correlation.

${ }^{*} \mathrm{P}<0.1,{ }^{* *} \mathrm{P}<0.05$, ${ }^{* * *} \mathrm{P}<0.01$.

$\mathrm{Hb}$ : hemoglobin, HAZ: Height for Age Z score, WHZ: Weight for Height Z score, BMIZ: Body Mass Index Z score.

deficiency anemia is believed to reduce cognitive abilities and school performance in children [16-19]. Lower iron stores and anemia related to $H$. pylori might in part explain the observed association between $H$. pylori infection and lower IQ scores. Another explanation may rely on the relationship between $H$. pylori infection and hypochlorhydria, which may increase the risk of diarrheal diseases resulting in malnutrition, iron deficiency anemia and eventually cognitive impairment [21]. Interestingly, $H$. pylori infection was recently linked with increased likelihood of Alzheimer disease [28] and mild cognitive impairment in older adults [29]. It was suggested that $H$. pylori eradication therapy might be beneficial to cognitive and functional status among such patients [30]. This association was explained by a cascade of events, starting with $H$. pylori-gastritis, resulting 
Table 4 Univariate analysis of IQ scores correlates - low SES village ${ }^{a}$

\begin{tabular}{lcccc}
\hline & & Full-Scale IQ & Non-Verbal IQ & Verbal IQ \\
\hline & N & Mean (SD) & Mean (SD) & Mean (SD) \\
\hline Sex & & & & \\
Males & 42 & $89.1(12.0)$ & $88.0(11.2)$ & $91.5(13.5)$ \\
Females & 41 & $91.1(12.1)$ & $88.8(10.8)$ & $94.3(14.0)$ \\
\hline
\end{tabular}

\begin{tabular}{llccc}
\hline Maternal education & & & & \\
$<10$ years & 68 & $88.8(11.9)$ & $87.8(10.1)$ & $90.8(13.8)$ \\
$\geq 10$ years & 15 & $96.0(11.2)^{* *}$ & $91.0(14.4)$ & $101.6(10.1)^{* *}$
\end{tabular}

\begin{tabular}{lcccc}
\hline Paternal education & & & & \\
$<10$ years & 50 & $89.7(13.7)$ & $89.0(11.6)$ & $91.5(15.1)$ \\
$\geq 10$ years & 22 & $91.6(10.4)$ & $86.7(14.1)$ & $97.2(10.4)$ \\
\hline Crowding index & & & & \\
$<$ median & 37 & $93.2(12.3)$ & $90.2(13.0)$ & $97.1(13.1)$ \\
$\geq$ median & 46 & $87.6(11.3)^{* *}$ & $86.9(8.9)$ & $89.5(13.5)^{* *}$ \\
\hline Composite SES & & & &
\end{tabular}

index

\begin{tabular}{lllll} 
Low SES & 38 & $88.3(12.9)$ & $88.0(10.7)$ & $90.0(14.7)$ \\
High SES & 45 & $91.6(11.1)$ & $88.8(11.3)$ & $95.4(12.6)^{*}$ \\
\hline
\end{tabular}

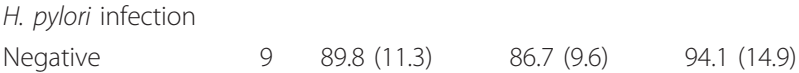

\begin{tabular}{lcccc} 
Negative & 9 & $89.8(11.3)$ & $86.7(9.6)$ & $94.1(14.9)$ \\
Positive & 63 & $90.2(12.5)$ & $89.1(11.4)$ & $92.4(14.1)$ \\
\hline Hb at early & 74 & $0.21^{*}$ & $0.30^{* *}$ & 0.14
\end{tabular}

childhood b

\begin{tabular}{lcccc}
\hline Current Hb level $^{b}$ & 83 & 0.08 & 0.03 & 0.11 \\
\hline $\begin{array}{l}\text { HAZ at early } \\
\text { childhood }^{b}\end{array}$ & 81 & $0.28^{* *}$ & $0.27^{* *}$ & $0.26^{* *}$ \\
\hline $\begin{array}{l}\text { WHZ at early } \\
\text { childhood }^{\text {b }}\end{array}$ & 80 & 0.04 & 0.05 & 0.04 \\
\hline Current BMIZ $^{\text {b }}$ & 83 & 0.03 & 0.05 & 0.01 \\
\hline
\end{tabular}

${ }^{\text {ap }}$ value were obtained by the Student $t$ test unless otherwise is specified.

${ }^{b}$ Pearson correlation.

${ }^{*} \mathrm{P}<0.1$, ${ }^{* *} \mathrm{P}<0.05$, ${ }^{* *} \mathrm{P}<0.01$.

$\mathrm{Hb}$ : hemoglobin, HAZ: Height for Age Z score, WHZ: Weight for Height Z score, BMIZ: Body Mass Index Z score.

in reduced absorption of vitamin B12 and folate which lead to accumulation of homocysteine levels, which is considered a risk factor of cognitive impairment in adults [29,31].

The inverse association between $H$. pylori infection and IQ parameters was evident only in children from the higher SES village. We believe that in this homogeneous subgroup, the role of other factors such as low maternal education and nutritional status is limited and does not mask the separate effect of $H$. pylori infection on cognitive development. We cannot rule out the possibility of lacking the statistical power to detect a significant association between $H$. pylori and IQ scores in the low SES village, in which almost $88 \%$ of the children were infected with $H$. pylori.

The role of the duration of $H$. pylori infection on cognitive function was not examined in the current study, since only 140 children were examined for $H$. pylori infection at both pre-school age and school age [32]. In this cohort of children, $H$. pylori infection was mostly acquired at pre-school age; $49.3 \%$ of the children were H. pylori positive at both age 3-5 years and 6-9 years, and $10.0 \%$ acquired the infection between these ages [32]. Hemoglobin levels were assessed as one of the covariates in our study, and a positive correlation was found between current hemoglobin levels and IQ scores in children from the high and intermediate SES villages, while in the low SES village hemoglobin levels in early childhood correlated positively with IQ scores. Although the impact of the duration of anemia on IQ scores was not assessed, we found a significant and positive correlation between hemoglobin level at the age of 6-9 years and hemoglobin levels in early childhood $(\mathrm{r}=0.25, \mathrm{P}=$ 0.001 ), suggesting that current hemoglobin level is likely influenced by past hemoglobin status.

A previous study showed that stunting, a measure of protein-energy malnutrition, in the first two years of life was associated with diminished cognitive function at school age [33]. Stunting is uncommon among the studied population (1.5\% by $18-30$ months). Our results among children from the low SES village indicate that even when stunting is rare, the greater height for age $\mathrm{Z}$ score, the better is the cognitive development.

We examined the novel finding on the association between $H$. pylori infection and cognitive function while broadly controlling for household and community socioeconomic characteristics, and nutritional status by stratification and multivariate analyses. We also restricted the participation in the study to children born at a gestational age of 34 week or more and a birth weight of $2 \mathrm{~kg}$ or more, and excluded children with medical conditions that might be associated with developmental outcomes to avoid confounding effect of these variables. The study population, Israeli Arabs, has unique characteristics. The infrastructure, health care and education systems are similar to those existing in developed countries while the rates of $H$. pylori infections and anemia are similar to those reported from developing countries. These can be regarded as strengths of the present study. Our study has also worth mentioning limitations. First, the small sample size limited the precision of the effect estimates, and limited our ability to assess the role of the duration of $H$. pylori infection and the duration of anemia on cognitive development. Residual confounders could also be still present. At this stage, we can not draw conclusions regarding a causal association between $H$. pylori and IQ scores.

\section{Conclusions}

Our findings indicate that $H$. pylori infection is associated with lower cognitive function at early school age, independent of socioeconomic and nutritional status, in 
Table 5 Multiple linear regression models of the association between $H$. pylori infection and IQ sores in Arab children, Israel

\begin{tabular}{|c|c|c|c|c|c|c|}
\hline & Full-Scale IQ & & Non-verbal IQ & & Verbal IQ & \\
\hline & $\beta$ & $95 \% \mathrm{Cl}$ & $\beta$ & $95 \% \mathrm{Cl}$ & $\beta$ & $95 \% \mathrm{Cl}$ \\
\hline \multicolumn{7}{|l|}{ High SES village $^{a}$} \\
\hline \multicolumn{7}{|l|}{ H. pylori infection } \\
\hline Negative & Reference & & Reference & & Reference & \\
\hline Positive & $-6.1^{* *}$ & $-11.4,-0.8$ & $-6.0^{* *}$ & $-11.1,-0.2$ & $-5.7^{* *}$ & $-10.8,-0.6$ \\
\hline \multicolumn{7}{|l|}{ Maternal education } \\
\hline$<10$ years & -2.4 & $-9.1,4.2$ & -5.4 & $-12.7,1.8$ & 0.9 & $-5.5,7.2$ \\
\hline$\geq 10$ years & Reference & & Reference & & Reference & \\
\hline Current $\mathrm{Hb}$ level & $3.5^{* *}$ & 0.3 .6 .7 & $3.4^{*}$ & $-0.1,6.9$ & $3.5^{* *}$ & $0.5,6.6$ \\
\hline \multicolumn{7}{|c|}{ Intermediate SES village ${ }^{b}$} \\
\hline \multicolumn{7}{|l|}{ H. pylori infection } \\
\hline Negative & Reference & & Reference & & Reference & $-1.2,7.1$ \\
\hline Positive & 1.8 & $-4.2,4.5$ & 0.3 & $-4.8,5.3$ & 3.0 & \\
\hline \multicolumn{7}{|l|}{ Maternal education } \\
\hline$<10$ years & $-5.6^{* *}$ & $-11.2,-2.2$ & -2.7 & $-8.4,2.9$ & $-7.9^{* *}$ & $-12.5,-3.2$ \\
\hline$\geq 10$ years & Reference & & Reference & & Reference & \\
\hline \multicolumn{7}{|l|}{$\overline{\text { Sex }}$} \\
\hline Males & $-6.6^{* *}$ & $-10.3,-1.2$ & $-8.6^{* *}$ & $-13.7,-3.5$ & $-4.3^{* *}$ & $-8.5,-0.2$ \\
\hline Females & Reference & & Reference & & Reference & \\
\hline Current $\mathrm{Hb}$ level & $2.3^{* *}$ & $0.4,4.3$ & $2.4^{* *}$ & $0.2,4.7$ & $1.9^{* *}$ & $0.03,3.7$ \\
\hline \multicolumn{7}{|l|}{ Low SES village ${ }^{c}$} \\
\hline \multicolumn{7}{|l|}{ H. pylori infection } \\
\hline Negative & Reference & & Reference & & Reference & \\
\hline Positive & 1.8 & $-6.6,10.3$ & 3.2 & $-4.4,10.8$ & 0.3 & $-9.5,10.2$ \\
\hline \multicolumn{7}{|l|}{ Maternal education } \\
\hline$<10$ years & -1.4 & $-9.8,7.1$ & 0.04 & $-7.5,7.6$ & -2.8 & $-12.7,7.0$ \\
\hline$\geq 10$ years & Reference & & Reference & & Reference & \\
\hline \multicolumn{7}{|l|}{ Crowding index } \\
\hline$<$ median & Reference & & Reference & & Reference & \\
\hline$\geq$ median & $-5.4^{*}$ & $-11.8,0.9$ & -2.5 & $-8.2,3.1$ & $-7.8^{* *}$ & $-15.2,-0.4$ \\
\hline $\mathrm{Hb}$ at early childhood & $4.2^{* *}$ & $0.2,8.2$ & $5.2^{* *}$ & $1.6,8.8$ & 3.0 & $-1.7,7.7$ \\
\hline HAZ at early childhood & $4.0^{* *}$ & $0.2,7.8$ & $3.3^{*}$ & $-0.1,6.8$ & $4.3^{*}$ & $-0.1,8.8$ \\
\hline
\end{tabular}

${ }^{*} P<0.1,{ }^{* *} P<0.05$, Hb: hemoglobin, HAZ: Height for Age $Z$ score.

${ }^{a}$ The multivariate analysis in the high SES included the variables $H$. pylori infection, maternal education, maternal age and current hemoglobin levels. ${ }^{b}$ In the intermediate SES village the adjusted model included the variables $H$. pylori infection, sex, maternal age, maternal education, and current hemoglobin level. The estimates did not changed when the variables "WHZ at early childhood" and "current BMIZ" were entered into the model. " In the low SES village the adjusted model included the variables $H$. pylori infection, maternal education, crowding index, hemoglobin levels and HAZ at early childhood.

relatively higher socioeconomic community. Further studies in other populations with larger samples are needed to confirm our results.

\section{Additional material}

Additional file 1: Characteristics of the three study villages, as published by the Israel Central Bureau of Statistics, 2006

\section{Acknowledgements}

The study was supported by a grant from the Chief Scientist of the Israel Ministry of Health (grant number 1-6159), and scholarships given to Khitam
Muhsen by Israel Ministry of Science and Technology, and Dan David foundation for her PhD thesis. The study sponsors had no role in the study design, collection of data, analysis and interpretation of results, neither in writing and submitting the manuscript.

The results of this study are part of Ms. Khitam Muhsen's PhD thesis at the Department of Epidemiology and Preventive Medicine, School of Public Health, Sackler Faculty of Medicine, Tel Aviv University.

The authors thank the fieldworkers Ola Abu-Shehab, Roza Marai, Shiraz Muhsen and Manal Jurban, for the contribution in the process of data collection, and Sophy Goren for her help in the data management.

\section{Author details}

'Department of Epidemiology and Preventive Medicine, School of Public Health, Sackler Faculty of Medicine, Tel-Aviv University, Ramat Aviv, Tel Aviv, 69978, Israel. ${ }^{2}$ Canada Israel Institute of Medical Research, Hebrew University 
Hadassah Medical School, Jerusalem, Israel. ${ }^{3}$ Clalit Health Services, Shomron sub-district, Hadera, Israel.

\section{Authors' contributions}

DC and KM conceived the study and planned it. DC supervised all aspects of its implementation and KM coordinated the study and led the writing of the manuscript. AA performed the cognitive assessments and AO supervised the cognitive assessment process. GA assisted substantially in the acquisition of data. DC, KM and AO worked on the data analysis and interpretation of the findings. All authors helped to conceptualize ideas, interpret findings, and review drafts of the manuscript. All authors read and approved the final manuscript

\section{Competing interests}

The authors declare that they have no competing interests.

Received: 10 September 2010 Accepted: 25 May 2011

Published: 25 May 2011

\section{References}

1. Berkman DS, Lescano AG, Gilman RH, Lopez SL, Black MM: Effects of stunting, diarrhoeal disease, and parasitic infection during infancy on cognition in late childhood: a follow-up study. Lancet 2002, 359:564-571.

2. Niehaus MD, Moore SR, Patrick PD, Derr LL, Lorntz B, Lima AA, Guerrant RL: Early childhood diarrhea is associated with diminished cognitive function 4 to 7 years later in children in a northeast Brazilian shantytown. Am J Trop Med Hyg 2002, 66:590-593.

3. Simsek Z, Zeyrek FY, Kurcer MA: Effect of Giardia infection on growth and psychomotor development of children aged 0-5 years. J Trop Pediatr 2004, 50:90-93.

4. Lorntz B, Soares AM, Moore SR, Pinkerton R, Gansneder B, Bovbjerg VE, Guyatt H, Lima AM, Guerrant RL: Early childhood diarrhea predicts impaired school performance. Pediatr Infect Dis J 2006, 25:513-520.

5. Rothenbacher D, Inceoglu J, Bode G, Brenner H: Acquisition of Helicobacter pylori infection in a high-risk population occurs within the first 2 years of life. J Pediatr 2000, 136:744-748.

6. Torres J, Perez-Perez G, Goodman KJ, Atherton JC, Gold BD, Harris PR, la Garza AM, Guarner J, Munoz O: A comprehensive review of the natural history of Helicobacter pylori infection in children. Arch Med Res 2000, 31:431-469.

7. Malaty HM, El-Kasabany A, Graham DY, Miller CC, Reddy SG, Srinivasan SR, Yamaoka Y, Berenson GS: Age at acquisition of Helicobacter pylori infection: a follow-up study from infancy to adulthood. Lancet 2002, 359:931-935.

8. Suerbaum S, Michetti P: Helicobacter pylori infection. N Engl J Med 2002, 347:1175-1186.

9. The International Agency for Research on Cancer: World Health Organization: Infection with Helicobacter pylori. 2009 [http://monographs. iarc.fr/ENG/Monographs/vol61/mono61-8.pdf].

10. Cardenas VM, Mulla ZD, Ortiz M, Graham DY: Iron deficiency and Helicobacter pylori infection in the United States. Am J Epidemio/ 2006, 163:127-134.

11. Choe YH, Kwon YS, Jung MK, Kang SK, Hwang TS, Hong YC: Helicobacter pylori-associated iron-deficiency anemia in adolescent female athletes. $J$ Pediatr 2001, 139:100-104.

12. Muhsen K, Barak M, Shifnaidel L, Nir A, Bassal R, Cohen D: Helicobacter pylori infection is associated with low serum ferritin levels in Israeli Arab children: a seroepidemiologic study. J Pediatr Gastroenterol Nutr 2009, 49:262-264.

13. Muhsen $\mathrm{K}$, Cohen D: Helicobacter pylori infection and iron stores: a systematic review and meta-analysis. Helicobacter 2008, 13:323-340.

14. Baggett HC, Parkinson AJ, Muth PT, Gold BD, Gessner BD: Endemic iron deficiency associated with Helicobacter pylori infection among schoolaged children in Alaska. Pediatrics 2006, 117:e396-e404.

15. Choi JW: Association between Helicobacter pylori infection and iron deficiency varies according to age in healthy adolescents. Acta Haematol 2007, 117:197-199.

16. Lozoff B, Jimenez $E$, Wolf AW: Long-term developmental outcome of infants with iron deficiency. N Engl J Med 1991, 325:687-694.
17. Lozoff B, Jimenez E, Smith JB: Double burden of iron deficiency in infancy and low socioeconomic status: a longitudinal analysis of cognitive test scores to age 19 years. Arch Pediatr Adolesc Med 2006, 160:1108-1113.

18. Palti H, Pevsner B, Adler B: Does anemia in infancy affect achievement on developmental and intelligence tests? Hum Biol 1983, 55:183-194.

19. Soemantri AG, Pollitt $E$, Kim I: Iron deficiency anemia and educational achievement. Am J Clin Nutr 1985, 42:1221-1228.

20. Lee A: Early influences and childhood development. Does helicobacter play a role? Helicobacter 2007, 12(Suppl 2):69-74.

21. Windle HJ, Kelleher D, Crabtree JE: Childhood Helicobacter pylori infection and growth impairment in developing countries: a vicious cycle? Pediatrics 2007, 119:e754-e759.

22. Israel Central Bureau of Statistics: The Arab Population 2008. State of Israel; 2011 [http://www.cbs.gov.il/www/statistical/arab_pop08.pdf], (Hebrew)

23. Muhsen Kh, Athamna A, Athamna M, Spungin-Bialik A, Cohen D: Prevalence and risk factors of Helicobacter pylori infection among healthy 3- to 5-year-old Israeli Arab children. Epidemiol Infect 2006, 134:990-996.

24. Israel Central Bureau of Statistics: Statistical Abstract of Israel 2008. Jerusalem. State of Israel; 2008 [http://www.cbs.gov.il/reader/], Publication number 59. Israel. (Hebrew) (Accessed 20, February 2009).

25. Israel Central Bureau of Statistics: Characterization and Classification of Local Authorities by the Socio-Economic Level of the Population 2006. Central Bureau of Statistics; 2009 [http://www.cbs.gov.il/www/publications/ local_authorities06/local_authorities_e.htm], (Accessed 6 march 2011).

26. Muhsen $\mathrm{K}, \mathrm{Na}$ 'amnih W: Health status of the Arab population in Israel 2008. Israel Center for Disease Control. Ministry of Health; 2010, Publication number 329. (Hebrew).

27. Muhsen K, BaraK M, Henig C, Alpert G, Ornoy A, Cohen D: Is the association between Helicobacter pylori infection and anemia age dependent? Helicobacter 2010, 15:467-472.

28. Kountouras J, Boziki M, Gavalas E, Zavos C, Deretzi G, Grigoriadis N, Tsolaki M, Chatzopoulos D, Katsinelos P, Tzilves D, Zabouri A, Michailidou I: Increased cerebrospinal fluid Helicobacter pylori antibody in Alzheimer's disease. Int J Neurosci 2009, 119:765-777.

29. Kountouras J, Tsolaki M, Boziki M, Gavalas E, Zavos C, Stergiopoulos C, Kapetanakis N, Chatzopoulos D, Venizelos I: Association between Helicobacter pylori infection and mild cognitive impairment. Eur J Neurol 2007, 14:976-982.

30. Kountouras J, Boziki M, Gavalas E, Zavos C, Grigoriadis N, Deretzi G, Tzilves D, Katsinelos P, Tsolaki M, Chatzopoulos D, Venizelos I: Eradication of Helicobacter pylori may be beneficial in the management of Alzheimer's disease. J Neurol 2009, 256:758-767.

31. Kountouras J, Gavalas E, Boziki M, Zavos C: Helicobacter pylori may be involved in cognitive impairment and dementia development through induction of atrophic gastritis, vitamin B-12 folate deficiency, and hyperhomocysteinemia sequence. Am J Clin Nutr 2007, 86:805-806.

32. Muhsen K, Athamna A, Bialik A, Alpert G, Cohen D: Presence of Helicobacter pylori in a sibling is associated with a long-term increased risk of H. pylori infection in Israeli Arab children. Helicobacter 2010, 15:108-113.

33. Mendez MA, Adair LS: Severity and timing of stunting in the first two years of life affect performance on cognitive tests in late childhood. J Nutr 1999, 129:1555-1562.

\section{Pre-publication history}

The pre-publication history for this paper can be accessed here: http://www.biomedcentral.com/1471-2431/11/43/prepub

doi:10.1186/1471-2431-11-43

Cite this article as: Muhsen et al: An association between Helicobacter pylori infection and cognitive function in children at early school age: a community-based study. BMC Pediatrics 2011 11:43. 